\title{
What shapes the elevational patterns of plant diversity on Mount Yatsugatake, Japan?
}

\author{
Yoshitaka Oishi ${ }^{1}$ \\ ${ }^{1}$ Fukui Prefectural University
}

September 11, 2020

\begin{abstract}
Aim: This study examined whether the hypotheses associated with species distribution could substantiate the elevational patterns of plants. Location: Mount Yatsugatake in central Japan. Taxon: Embryophyte Methods: The species richness of plant groups (trees, shrubs, herbs, ferns, and bryophytes) was investigated within study plots established at 200-m elevational intervals from $1800 \mathrm{~m}$ to $2800 \mathrm{~m}$. The changes in species richness (alpha diversity) with elevation were analysed in relation to climatic factors and the hypotheses pertaining to the elevational distribution of plants, i.e., mass effect, mid-domain effect, and Rapoport's elevational rule. The elevational patterns of beta diversity, plant functional types, and elevational ranges of plant groups were examined. Results: The comparison of alpha and beta diversity revealed that the different plant groups variably responded to elevation; the alpha diversity of trees and ferns decreased, that of herbs increased, whereas that of shrubs and bryophytes showed a positive and negative quadratic curve, respectively. The beta diversity of shrubs, herbs, and moss abruptly increased above the subalpine-alpine transition zone. In accordance with these changes, the dominance of evergreen shrubs and graminoids increased, whereas that of liverworts decreased at the elevation zone. Regarding the elevational ranges, no plant group showed a wider elevational range at higher elevations. Main conclusions: The elevational patterns of the plant groups were determined by the climatic factors and their effects on plant-plant interactions. Notably, these interactions were presented based on the changes in plant functional types, supporting the elevational patterns of plant diversity. Our finding indicates the importance of studies on elevational patterns using multi-plant groups and multiple indices of plant diversity.
\end{abstract}

\section{INTRODUCTION}

Montane ecosystems are seriously threatened by global warming (Dullinger et al., 2012; Engler et al., 2011; Nogués-Bravo, Araújo, Errea, \& Martínez-Rica, 2007), which has caused an upward shift in the distribution of warm-adapted plants and animals and has decreased the abundance of cold-adapted ones. In the mountainous regions of Europe, $36-55 \%$ of the alpine plant species, $31-51 \%$ of the subalpine species, and $19-46 \%$ of the montane species are expected to lose more than $80 \%$ of their suitable habitat by $2070-2100$ due to climate change (Engler et al., 2011). Owing to the reduced opportunity for species upward migration, these predictions suggest a more pronounced influence of global warming on biota at higher elevations (Engler et al., 2011).

Elevation is the major factor that determines plant diversity in mountainous areas (Bhattarai \& Vetaas, 2003; Grytnes, Heegaard, \& Ihlen, 2006; Jiang, Ma, Liu, \& Tang, 2018; Körner, 2007; Lee, Chun, Song, \& Cho, 2013; Lee \& La Roi, 1979; Sánchez-Gonzalez \& Lopez-Mata, 2005; Zhou et al., 2019). These patterns are influenced by multiple factors including climate, local environments, spatial aspects, evolutionary processes, and biotic interactions (Culmsee \& Leuschner, 2013; Grytnes, Heegaard, \& Romdal, 2008; Lomolino, 2001; Song et al., 2020; Sun et al., 2013; Trigas, Panitsa, \& Tsiftsis, 2013).

Plant responses to these factors are often explained by several hypotheses such as the mass effect, mid-domain effect, and Rapoport's elevational rule. According to the mass effect hypothesis, species that cannot maintain 
viable populations in sink areas populate those adjacent to source areas occupied by larger populations (Grytnes, Heegaard, \& Ihlen, 2006; Shmida \& Wilson, 1985). These populations increase species richness, even to its maximum values around ecotones, where two different communities meet. Unlike this foregoing theory, the mid-domain effect hypothesis assumes a random distribution of species within a geometrically constrained domain such as that between the summit and base of a mountain. Consequently, species richness peaks in the middle of the domain because of the increasing overlap of species distributions towards the centre (Colwell \& Lees, 2000; Colwell, Rahbek, \& Gotelli, 2004). Rapoport's elevational rule postulates that species at higher elevations can withstand a broad range of climatic conditions occurring across a high range of elevations (Stevens, 1992).

However, plant groups show disparate responses to elevation, and even plants within a single group have dissimilar elevational distributions across different areas (Bhattarai \& Vetaas, 2003; Bruun et al., 2006; Grau, Grytnes, \& Birks, 2007; Grytnes, Heegaard, \& Ihlen, 2006; Lee et al., 2013; Lee \& La Roi, 1979; Miyajima, Sato, \& Takahashi, 2007; Sanchez-Gonzalez \& Lopez-Mata, 2005; Zhou et al., 2019). These diverse responses indicate that the applicability of the aforementioned hypotheses may depend on the plant group and growth area. This highlights the importance of examining the elevational distribution of multi-plant groups in areas with erratic climate and diverse vegetation in understanding the drivers of plant diversity.

The mountainous areas of Japan experience strong winds and heavy snowfall due to the influence of jet streams and winter monsoons (Manabe, 1957; Riehl, 1962; Ueda, Kibe, Saitoh, \& Inoue, 2015). This climate allows a single Japanese stone pine tree species (Pinus pumila Regel) to become dominant, owing to its resistance to wind and snow, at the subalpine-alpine transition zone (Okitsu, 1984). According to the mass effect hypothesis, this is a considerable change from the expected plant distribution, because the subalpine-alpine transition zones often harbour high species richness consisting of co-existing alpine and subalpine plants, resulting in hump-shaped patterns of species richness along these elevations (Grytnes, 2003; Grytnes, Heegaard, \& Ihlen, 2006). However, this hump-shaped pattern has become suppressed due to the dominance of stone pine trees shading out other plants. These patterns further question the applicability of the hypotheses for predicting the elevational patterns of plants.

In this study, we investigated the elevational distribution of multi-plant groups in the Yatsugatake Mountains of Japan to determine whether the pertinent elevation hypotheses mentioned (i.e. mass effect, mid-domain effect, and Rapoport's elevational rule) could substantiate the existing elevational patterns of the plant groups occurring there. The applicability of these hypotheses was examined based on the comparison between the actual elevational patterns of the plant groups and those expected by the following hypotheses:

Hypothesis 1: If the elevational patterns of plants follow the mass effect hypothesis, the highest species richness will be located around ecotones such as the intermediate zone between the subalpine and alpine zones.

Hypothesis 2: If the mid-domain effect hypothesis is applied to the elevational patterns of the plants, the distribution patterns will correspond to those expected by the random distribution of species between the summit and base of a mountain.

Hypothesis 3: If the distribution of plant species can be explained by Rapoport's elevational rule, alpine species will exhibit larger elevational ranges than species at lower elevations.

Hypothesis 4: If the three elevational hypotheses do not apply to the observed patterns of plant distribution, other factors such as climate will largely determine their distribution.

\section{MATERIALS AND METHODS}

\subsection{Study site}

The study was conducted in the Yatsugatake Mountains in central Japan. The highest peak of these mountains is the $2899-\mathrm{m}$ summit of Mount Akadake (35deg58.259' $\left.\mathrm{N}, 138^{\circ} 22.223^{\prime} \mathrm{E}\right)$. The vegetation in the Yatsugatake Mountains is classified into the following four types: temperate deciduous forest dominated by 
Quercus crispula and Larix kaempferi below $1800 \mathrm{~m}$; subalpine conifer forest dominated by Tsuga diversifolia, Abies veitchii, andAbies mariesii f. hayachinensis at $1800-2600 \mathrm{~m}$; alpine dwarf pine scrub dominated by $P$. pumila at $\sim 2600-2800 \mathrm{~m}$; and alpine meadow with turf-rock vegetation at $\sim 2800-2900 \mathrm{~m}$. The subalpine-alpine ecotone at $\sim 2700 \mathrm{~m}$ is widely covered by $P$. pumila . The highest and lowest mean temperatures, obtained from the nearest weather station at $1350 \mathrm{~m}$, are $19.2{ }^{\circ} \mathrm{C}$ in August and $-5.3 \operatorname{degC}$ in January, respectively, and the mean precipitation is $1439.9 \mathrm{~mm} /$ year (Japan Meteorological Agency, 2018).

\subsection{Field survey}

Twelve $10 \mathrm{~m} \times 10 \mathrm{~m}$ study plots were established at 200-m elevational intervals from $1800 \mathrm{~m}$ to $2800 \mathrm{~m}$, extending from the east to the west of the Yatsugatake Mountains. The plants in each plot were identified based on the taxonomic groups: trees, shrubs, herbs, ferns, and bryophytes. Ferns and bryophytes included both epiphytic and terrestrial species. Epiphytic species were recorded up to $2.0 \mathrm{~m}$ from the ground.

To examine the influence of climate on plant diversity, temperature and relative humidity $(\mathrm{RH})$ were measured in each plot at ${ }^{\sim} 5 \mathrm{~cm}$ above the ground at 4-h intervals throughout the year, obtained using HOBO U23 Pro v2 temperature/relative humidity data loggers (Onset Computer Corporation, Bourne, MA, USA). To reduce the influence of sunlight on the measurements, the data loggers were covered by a CO-RS1 solar radiation shield (Onset Computer Corporation). Based on the measurements of temperature and RH, the following climatic variables were calculated: mean annual temperature (Tempann), mean temperature during the growing season $\left(\right.$ Temp grow $_{\text {) }}$, mean temperature during the snow season $\left(\right.$ Temp $_{\text {snow }}$ ), mean annual $\mathrm{RH}$ $\left(\mathrm{RH}_{\mathrm{ann}}\right)$, mean $\mathrm{RH}$ during the growing season $\left(\mathrm{RH}_{\text {grow }}\right)$, mean $\mathrm{RH}$ during the snow season $\left(\mathrm{RH}_{\text {snow }}\right)$, and the duration of the snow season (snow cover). The series of snow-cover days with over $90 \% \mathrm{RH}$ was defined as the snow season. This definition was based on a primary experiment that buried the data loggers under a snow pack. The remaining days were defined as the growing season.

\subsection{Statistical analyses}

The alpha diversity, beta diversity, dominance of plant functional types, and elevational range of each plant group, as well as the total number of plants, were calculated to examine the validity of the existing hypotheses. Alpha diversity was defined as the species richness of each plant group within a plot, and its correlation with the elevation was fitted by generalised linear models (GLMs) with log-link function and Poisson distribution. Both the linear and second-order polynomial models were constructed, and the final model was selected as that with significant coefficients and higher Akaike information criterion (AIC) values. If no model had significant coefficients, then that with the lowest AIC value was adopted. The influence of climatic factors on plant diversity was also analysed using GLMs with log-link function and Poisson distribution. The explanatory variables used in these models were measured as the climatic factors having a stronger correlation with alpha diversity $(r>0.5)$. Beta diversity was evaluated using the $\beta_{\sin }$ index, considering that this metric excellently performs under various criteria (Koleff, Gaston, \& Lennon, 2003). The $\beta_{\text {sin }}$ index was calculated between adjacent plots as follows:

$\beta_{\sin }=1-\frac{a}{(\min [b, c]+a)}(1)$

where, $a$ is the total number of species found in both plots; $b$ is the number of species found in the focal plot; and $c$ is the number of species found in the other plot.

The elevational patterns associated with alpha and beta diversity were further discussed in relation to changes in plant functional types. Plant functional types are groups of species that respond similarly to environmental and biotic changes (Duckworth, Kent, \& Ramsay, 2000). These responses were used to characterize the elevational patterns of plant groups (Bruun et al., 2006; Sánchez-González \& López-Mata, 2005; Zhou et al., 2019). This study classified trees, shrubs, herbs, and bryophytes into the following functional types: evergreen and deciduous trees, evergreen and deciduous shrubs, forbs and graminoids, and mosses and liverworts, respectively. The dominance of plant functional groups was calculated as the ratios of the species richness of each functional type to the total species richness of the plant group. The dominance was then plotted against elevation. 
To test the applicability of the mid-domain effect to elevational distribution, the discrepancy between the observed results and those predicted by the mid-domain effect was determined using the null model, which was based on the discrete mid-domain effect model (Colwell \& Hurtt, 1994). The predicted mean species richness was calculated by 9999 Monte Carlo simulations with the RangeModel software version 5.0 (Colwell, 2006). The predicted values were plotted against elevation and correlated with the observed alpha diversity using Pearson's correlation.

Finally, the applicability of Rapoport's elevational rule to elevational distribution was examined based on the elevational range of each plant group. The elevational range was defined as the mean difference between the highest and lowest elevations of all the recorded species in each plot and was calculated as follows:

Elevational range $=\frac{\sum_{i=1}^{n}\left(H_{i}-L_{i}\right)}{n}(2)$

where, $n$ is the total number of species recorded in a plot; $H_{i}$ is the highest elevation where the $i$ th species was recorded; and $L_{i}$ is the lowest elevation where the $i$ th species was recorded. The highest and lowest elevations were based on herbarium specimens (Nagoya University Museum; NUM-Bt) collected in central Japan (Chubu, Kinki, and Kanto regions), plant diversity databases (Biodiversity centre of Japan, 2018), and plant survey reports from the studied region (Akiyama, 1983, 1984; Hattori, 1958; Inoue, 1981; Kodama, 1971, 1972; Masuzaki \& Katagiri, 2010; Takaki, Amakawa, Osada, \& Sakuma, 1970).

\section{RESULTS}

\subsection{Species richness, elevational distribution, and climatic factors}

A total of 260 plant species (20 tree species, 17 shrubs, 49 herbs, 11 ferns, and 163 bryophytes) were found in the study area. The species richness per plot (mean \pm standard deviation) of the trees, shrubs, herbs, ferns, and bryophytes was $5.00 \pm 1.81,2.50 \pm 2.32,9.42 \pm 5.14,2.00 \pm 1.86$, and $41.00 \pm 17.00$, respectively (Table S1).

The Pearson's correlation analysis between climatic factors and elevation showed that elevation was positively correlated with the snow cover $(r=0.769 ; p<0.01)$ but negatively correlated with Tempann $(r=-0.862$; $p<0.01)$ and Temp grow $(r=-0.822 ; p<0.01)$. In contrast, no significant correlations were observed between elevation and the $\mathrm{RH}$ variables $\left(\mathrm{RH}_{\mathrm{ann}}, \mathrm{RH}_{\text {grow }}\right.$, and $\left.\mathrm{RH}_{\text {snow }}\right)$.

\subsection{Alpha diversity}

The alpha diversities of the plant groups exhibited different responses to elevational distribution (Figure 1). All the coefficients, except that for ferns, in the GLMs were significant. Both the total and tree alpha diversities linearly decreased with elevation (Figure 1a, 1b), whereas that of herbs increased (Figure 1d). The alpha diversities of shrubs and bryophytes were fitted by second-order polynomial and that of shrubs showed a positive quadratic curve with the highest value at an elevation of $2800 \mathrm{~m}$ (Figure 1c), whereas that of the bryophytes showed a negative quadratic curve displaying a hump-shaped pattern with higher values at $2000 \mathrm{~m}$ (Figure 1f). Notably, the alpha diversity of herbs increased with elevation overall; however, a lower value was recorded at one $2800 \mathrm{~m}$-plot where the stone pine trees dominated.

The results for alpha diversity and climatic factors obtained using GLMs are shown in Table 1. The variable Temp $_{\text {ann }}$ and Temp $p_{\text {snow }}$ had significant positive effects on the alpha diversities of trees and ferns. The alpha diversity of shrubs was negatively correlated with $\mathrm{RH}_{\text {grow }}$, whereas that of herbs was positively correlated with the snow cover and that of bryophytes was positively correlated with $\mathrm{RH}_{\text {grow }}$.

\subsection{Beta diversity}

When beta diversity (based on the $\mathrm{B}_{\text {sin }}$ index) was plotted against elevation (Figure 2, Table S2), the $\beta_{\text {sin }}$ indices of shrubs and ferns were not calculated in several plots because of the zero denominator in the fraction of $\beta_{\sin }$ (Figure 2c, 2e). Although $\beta_{\sin }$ for the total number of species gradually increased with elevation (Figure 2a), those for shrubs and herbs strongly increased above the subalpine-alpine transition zone (Figure 2c, 2d). 


\subsection{Functional types}

All dominance results of plant functional types presented clear changes at 2600-2800 m (Figure 3, Table S3). The dominance of evergreen trees and liverworts decreased in this elevation range (Figure 3a, 3d), whereas that of evergreen shrubs and graminoids increased (Figure 3b, 3c).

\subsection{Mid-domain effect}

Species richness (alpha diversity) was predicted based on the mid-domain effect to examine the applicability of this hypothesis to the sampling site (Figure 1, Table S4). In all the plant groups, the correlations between the observed species richness and those predicted with the mid-domain effect were not significant (total: $r$ $=0.160, p=0.62$; trees: $r=-0.031, p=0.92$; shrubs: $r=-0.738, p<0.01$; herbs: $r=-0.074, p=0.82$; ferns: $r=0.110, p=0.74$; and bryophytes: $r=0.276, p=0.38$ ). Thus, the elevational patterns of alpha diversity in all the plant groups were different from those predicted with the mid-domain effect.

\subsection{Elevational range}

The mean elevational range of each plant group was calculated and plotted as a function of elevation (Figure 4, Table S5). The results showed that none of the plant groups had a wider elevational range at higher elevations.

\section{DISCUSSION}

In this study, we investigated the elevational distribution of multi-plant groups in the Yatsugatake Mountains to determine whether pertinent elevation hypotheses could substantiate the existing elevational patterns of the plant groups occurring there. The plant groups showed different responses to the elevational gradients and climatic factors in the study site. Regarding the elevational changes in alpha diversity, none of the plant groups exhibited elevational patterns corresponding to those expected based on mass and mid-domain effects. The elevational range of all the plant groups did not increase with elevation, disproving the application of Rapoport's elevational rule to the distribution of plant groups in the study site. In contrast, the alpha diversity of all the plant groups was significantly affected by the climatic factors.

\subsection{Elevational patterns of plants}

Contrary to the expected elevational patterns by mass effect, the alpha diversity of all the plant groups, except that for the shrubs, did not clearly show the highest values at the subalpine-alpine ecotone (ca. 2600-2800 m). Instead, these patterns were largely explained by climatic factors. These associations were examined in relation to the ecology of each plant group.

The alpha diversity of trees decreased with elevation (Figure 1b), and this elevational pattern was explained by Tempann. These results are supported by a previous study that the elevational range of trees can be determined by temperature, which strongly affects their physiochemical activities (Körner, 2003). This obvious influence of Tempann on tree diversity may have led to the relatively constant changes in the beta diversities as compared to those of other plant groups (Figure 2), because Tempann linearly decreases with elevation.

Similar to the results for trees, the alpha diversity of ferns also decreased with elevation (Figure 1e), which was attributed to Temp $\mathrm{snow}_{\text {in }}$ the GLM. These results are consistent with previous reports that fern species richness decreased at higher elevation and lower temperature in central Japan (Tanaka \& Sato, 2013, 2014).

In contrast to the results for the trees and ferns, the alpha diversity of the herbs was positively correlated with elevation (Figure 1d). Given that snow cover positively affected herb diversity in the GLM, the species richness of the herbs increased with environmental changes related to snowfall, such as soil moisture and canopy closure. It has been known that long periods of snow augment soil moisture (Hardy et al., 2001), which is essential for the proliferation of herbs in arctic-alpine habitats (Litaor, Williams, \& Seastedt, 2008; NabeNielsen et al., 2017; Roux, Aalto, \& Luoto, 2013). Snow cover may decrease canopy closure by suppressing tree canopy growth (Song, Hogan, Brown, Cao, \& Yang, 2017), which increases light intensity and reduces 
the accumulation of litter on the forest floor. These changes enhance herb species richness by guaranteeing the photosynthesis and germination of herbs (Speziale, Ruggiero, \& Ezcurra, 2010).

However, the positive effects of snow cover on herb richness may be reduced at subalpine-alpine transition zone where a shrub species ( $P$. pumila) densely grows near the ground, since they shade out herbs. This effect explains the lower species richness of herbs at one 2800-m plot where the stone pine trees cover almost the entire plot. In fact, herbs at this plot were recorded in small areas uncovered by the stone pine trees; as a result, the herb layer mainly consisted of graminoids (Table S3), which prefer to grow in open areas (Roberts \& Zhu, 2002; Thomas, Halpern, Falk, Liguori, \& Austin, 1999).

The beta diversity of the herbs presented the highest values around the subalpine-alpine ecotones (Figure $2 \mathrm{~d}$ ). This is because shade-tolerant species dominate below the forest boundary, whereas species that can tolerate low temperatures (Jiang, Ma, Liu, \& Tang, 2018) and light stress (e.g., graminoids growing in open areas between shrubs) prevail above it.

The alpha diversity of the shrubs rapidly increased from the subalpine-alpine to the alpine zone (Figure 1c). This elevational pattern was explained by the $\mathrm{RH}_{\text {grow }}$ in the GLM. Considering that canopy closure diminishes shrub diversity (Speziale, Ruggiero, \& Ezcurra, 2010) and intensifies air humidity (Jung et al., 2017), $\mathrm{RH}_{\text {grow }}$ may be selected in the GLM as a surrogate that represents the negative influence of canopy closure on shrub richness. Accordingly, this change in canopy closure from dense to open may be attributed to the rapid increase in the beta diversity of the shrubs around the subalpine-alpine transition zone (Figure 2c).

Only the bryophytes showed a hump-shaped change in alpha diversity with increasing elevation (Figure 1f). The GLM results demonstrated that this pattern could be attributed to $\mathrm{RH}_{\text {grow }}$, which is consistent with the results of a previous report suggesting that water stress is a major determinant of bryophyte diversity (Grau, Grytnes, \& Birks, 2007). Therefore, alpha diversity was the highest in the subalpine zone with the highest RH. The higher beta diversity of bryophytes around the subalpine-alpine ecotones (Figure 2f) is discussed with the changes in functional types in the following section.

\subsection{Functional types and plant-plant interactions}

The elevational patterns of plant diversity are further discussed in relation to plant functional types. Evergreen shrub species (P. pumila) began to dominate at the subalpine-alpine ecotone (ca. 2600-2800 m) instead of evergreen conifer trees. These changes are displayed by the increase in the dominance of evergreen shrubs accompanied by the decrease in that of evergreen trees (Figure 3a, 3b). In accordance with these changes, the dominance of graminoids increased, whereas that of liverworts decreased at these elevations (Figure 3c, 3d). These associations can be attributed to the improved light availability and reduced humidity owing to the change from a close to an open canopy. Graminoids dominate open forests (Roberts \& Zhu, 2002; Thomas, Halpern, Falk, Liguori, \& Austin, 1999) and are more resistant to drought stress than forbs (Rosbakh et al., 2017), whereas liverworts are more vulnerable to drought stress (Grau Grytnes, \& Birks, 2007; Jan \& Wolf, 1993) and are more shaded-adapted (Marschall \& Proctor, 2004) than mosses. Given the characteristics of these functional types, the reduced canopy caused the increase in light availability (except for under the $P$. pumila cover) and drought stress at the subalpine-alpine ecotone, leading to the changes in the functional types of herbs and bryophytes. These changes in plant functional types support the increase in the beta diversity of herbs and bryophytes at 2600-2800 m (Figure 2d, 2f).

\subsection{Mass effect on elevational patterns}

Among all the plant groups, only the shrubs clearly showed the highest alpha diversity around the subalpinealpine transition zone (Figure 1), which contradicts the expected patterns based on mass effect (Hypothesis 1). These results may be explained by the combined influence of plant-plant interactions and climatic factors, as the dominance of stone pine trees in the transition zone inhibits the establishment of small plant species by shading and curbs the increase in the species richness, as discussed in section 4.1.

\subsection{Applicability of hypotheses for elevational patterns}


The results of the discrete mid-domain effect model revealed that the alpha diversity of all the plant groups differed from those expected by the mid-domain effect hypothesis (Figure 1). Furthermore, we found no relationship between the elevational range and alpha diversity of all the plant groups, and none of the plant groups had a wider elevational range in the alpine area (Figure 4), which contradicted those expected by Rapoport's elevational rule.

The lack of applicability of the mid-domain effect and Rapoport's rule to elevational patterns is attributed to the simple assumptions of these hypotheses; the former excludes any effects of gradients on expected patterns (Colwell, Rahbek, \& Gotelli, 2004), whereas the latter fails when species distribution is affected by the interaction of several factors including climate (Bhattarai \& Vetaas, 2006; Grau, Grytnes, \& Birks, 2007). Specifically, in the study area, strong winds and heavy snowfall at higher elevations increased the differences in climate between lower and higher elevations. These differences can enhance the influence of climate and the related plant-plant interactions on the elevational patterns of plants.

\subsection{Determinants of plant elevational patterns}

In summary, this study showed that the changes in the elevational distribution of plants groups in the Yatsugatake Mountains were different from those predicted with the pertinent hypotheses but were rather directly and indirectly influenced by climate and its effect on plant-plant interactions. Therefore, our results correspond to Hypothesis 4, indicating that the applicability of hypotheses for predicting plant elevational patterns largely depends on the environment in the targeted study site.

Our findings demonstrated that the plant groups responded differently to different elevational gradients. These differences may amplify the effects of climate change in montane ecosystems. In particular, given that the plant diversity on the subalpine-alpine transition zone was based on the balance of plant-plant interactions, this ecotone may be vulnerable to climate change.

Previous studies reported that plant-plant interactions change the alpha diversity of plant groups among elevations (Bruun et al., 2006; Stehn, Webster, Glime, \& Jenkins, 2010; Sun et al., 2013); this study went one step further and revealed that these interactions affect the beta diversity and dominance of plant functional types. These results imply the importance of studies on elevational patterns using multi-plant groups and multiple indices of plant diversity (e.g, alpha and beta diversity and functional types) to comprehend the interactions among plant groups. Specifically, given that plant functional types consist of those species with similar characteristics and are applied to other areas with different flora, our results linked to functional types can be useful to understand the mechanisms that shape plant diversity along elevations.

TABLE 1. Relationships between the alpha diversity of different plant groups and climatic factors in the Yatsugatake Mountains in central Japan, obtained using generalised linear models.

\begin{tabular}{|c|c|c|c|c|c|}
\hline Plant Group & Explanatory Variable & Estimate & Standard Error & z-Value & $p$-Value \\
\hline \multirow[t]{4}{*}{ Total } & Tempann & $1.33 \times 10^{-1}$ & $4.58 \times 10^{-2}$ & 2.91 & 0.00357 \\
\hline & $\mathrm{RH}_{\mathrm{ann}}$ & $1.26 \times 10^{-1}$ & $3.92 \times 10^{-2}$ & 3.22 & 0.00127 \\
\hline & Temp $_{\text {snow }}$ & $-5.73 \times 10^{-2}$ & $4.03 \times 10^{-2}$ & -1.42 & 15.5 \\
\hline & Intercept & $-2.94 \times 10^{-1}$ & 7.72 & -3.81 & $<0.001$ \\
\hline \multirow[t]{2}{*}{ Trees } & Tempann & $2.06 \times 10^{-1}$ & $9.48 \times 10^{-2}$ & 2.18 & 0.0296 \\
\hline & Intercept & $-5.54 \times 10$ & $2.62 \times 10$ & -2.11 & 0.0347 \\
\hline \multirow[t]{2}{*}{ Shrubs } & $\mathrm{RH}_{\text {grow }}$ & $-2.34 \times 10^{-1}$ & $6.89 \times 10^{-2}$ & -3.39 & $<0.001$ \\
\hline & Intercept & $2.24 \times 10$ & 6.28 & 3.57 & $<0.001$ \\
\hline \multirow[t]{2}{*}{ Herbs } & Snow cover & $1.54 \times 10^{-2}$ & $4.91 \times 10^{-3}$ & 3.15 & 0.00165 \\
\hline & Intercept & $-4.14 \times 10^{-1}$ & $8.63 \times 10^{-1}$ & $-4.80 \times 10^{-1}$ & 0.632 \\
\hline \multirow[t]{2}{*}{ Ferns } & Temp $_{\text {snow }}$ & $3.60 \times 10^{-1}$ & $1.64 \times 10^{-1}$ & 2.20 & 0.028 \\
\hline & Intercept & $-9.70 \times 10$ & $4.45 \times 10$ & -2.18 & 0.0294 \\
\hline \multirow[t]{2}{*}{ Bryophytes } & $\mathrm{RH}_{\text {grow }}$ & $1.05 \times 10^{-1}$ & $1.84 \times 10^{-2}$ & 5.74 & $<0.001$ \\
\hline & Intercept & -6.10 & 1.72 & -3.55 & $<0.001$ \\
\hline
\end{tabular}


Coefficients of generalized linear models and their significance are presented: Tempann, mean annual tem-

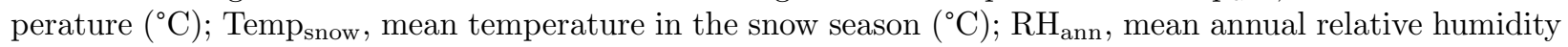
(\%); $\mathrm{RH}_{\text {grow }}$, mean relative humidity in the growing season (\%); and Snow cover, snow cover period (days).

\section{FIGURE LEGENDS}

Figure 1. Elevational changes in the alpha diversity of plant groups in the Yatsugatake Mountains in central Japan: (a) total, (b) trees, (c) shrubs, (d) herbs, (e) ferns, and (f) bryophytes. The calculated alpha diversity based on the mid-domain effect is denoted by an asterisk $(*)$. In illustrating the alpha diversity, generalised linear models were used to explore the pertinent changes with elevation. When the coefficient was significant, a regression curve was added to the illustration, and a $95 \%$ confidence interval was calculated and coloured.

Figure 2. Elevational changes in the beta diversity ( $\beta_{\sin }$ indices) of plant groups in the Yatsugatake Mountains in central Japan: (a) total, (b) trees, (c) shrubs, (d) herbs, (e) ferns, and (f) bryophytes.

Figure 3. Elevational changes in the dominance of plant functional types in the Yatsugatake Mountains of central Japan: (a) evergreen trees, (b) evergreen shrubs, (c) graminoids, (d) liverworts.

Figure 4. Elevational changes in the distribution range of plant groups in the Yatsugatake Mountains in central Japan: (a) total, (b) trees, (c) shrubs, (d) herbs, (e) ferns, and (f) bryophytes.
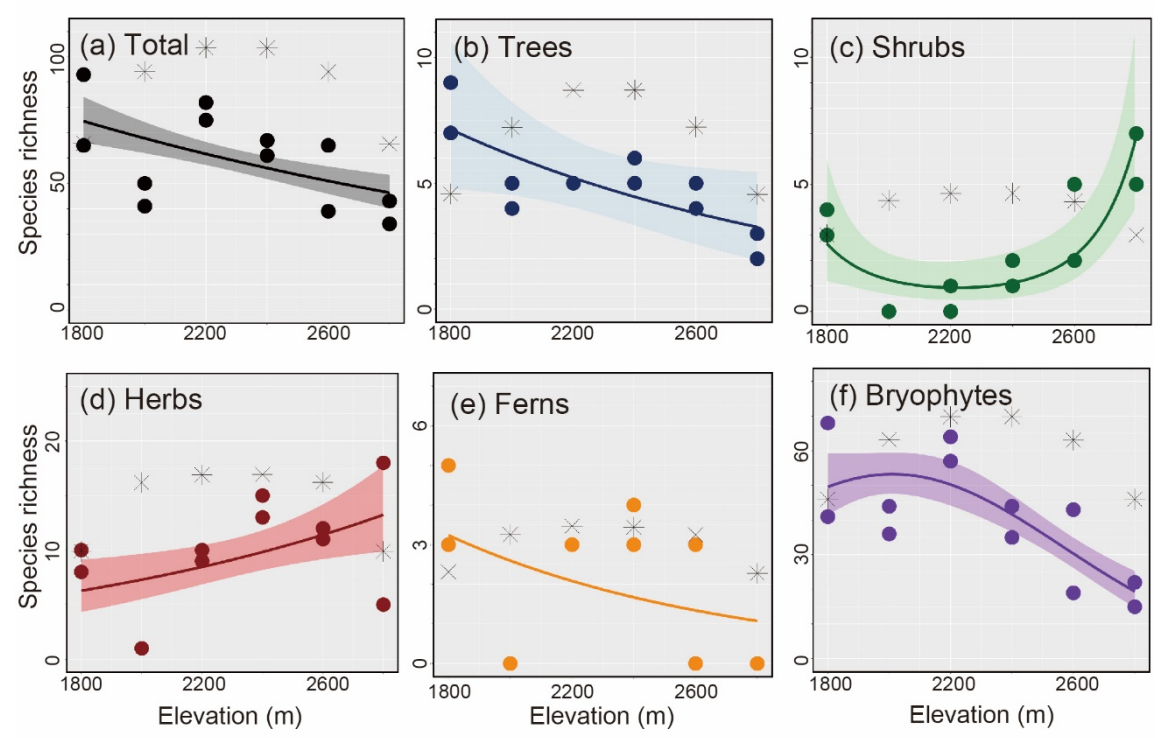

Figure 1

Figure 1. 

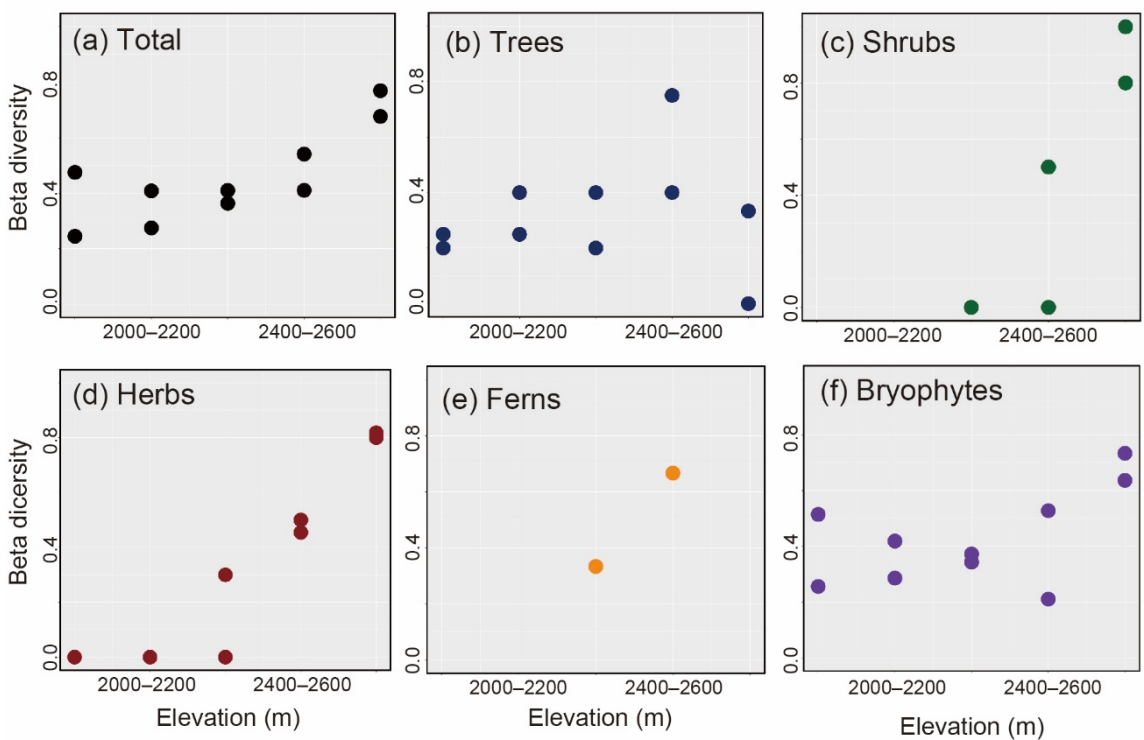

Figure 2

Figure 2. 

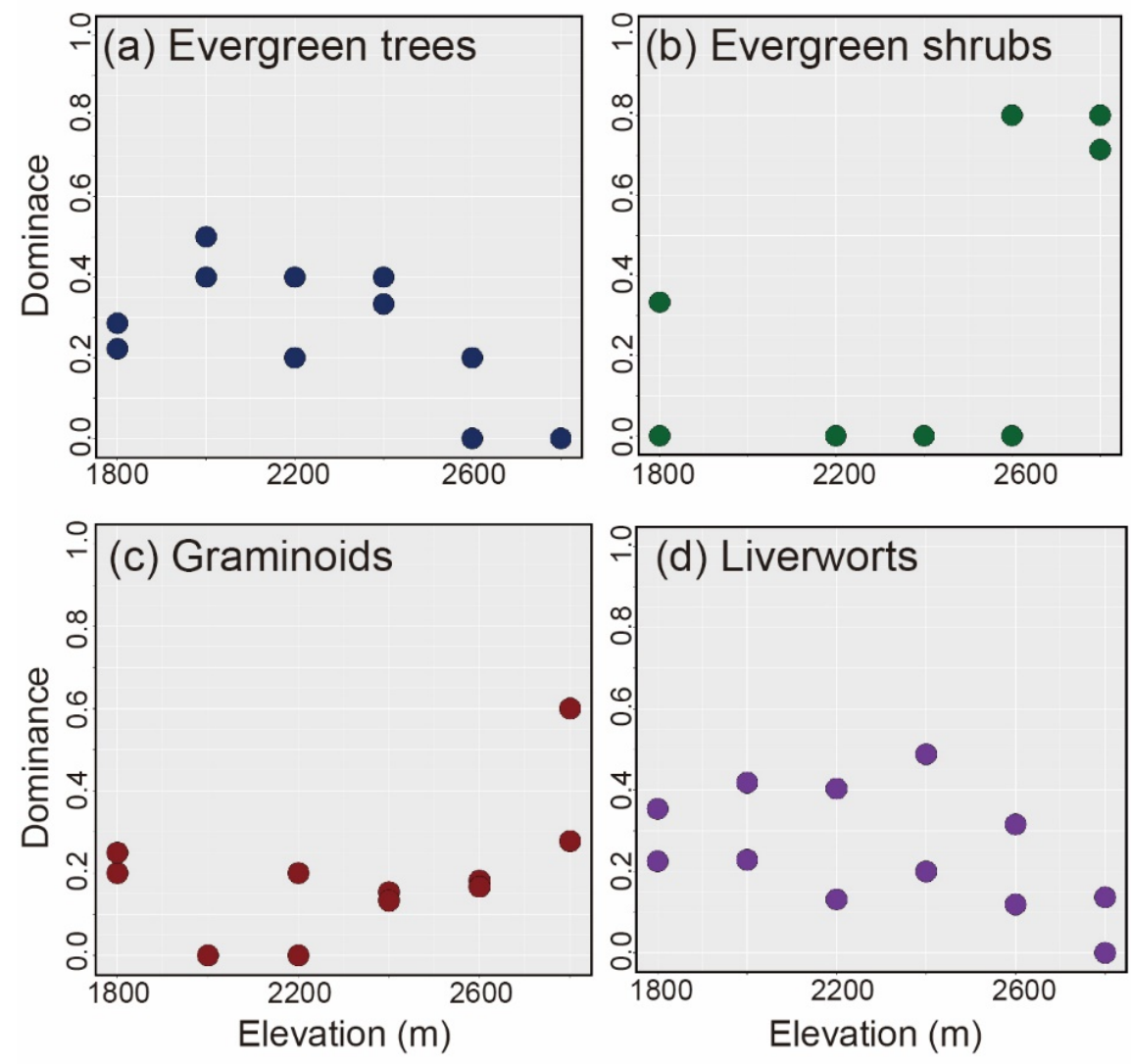

Figure 3

Figure 3 . 

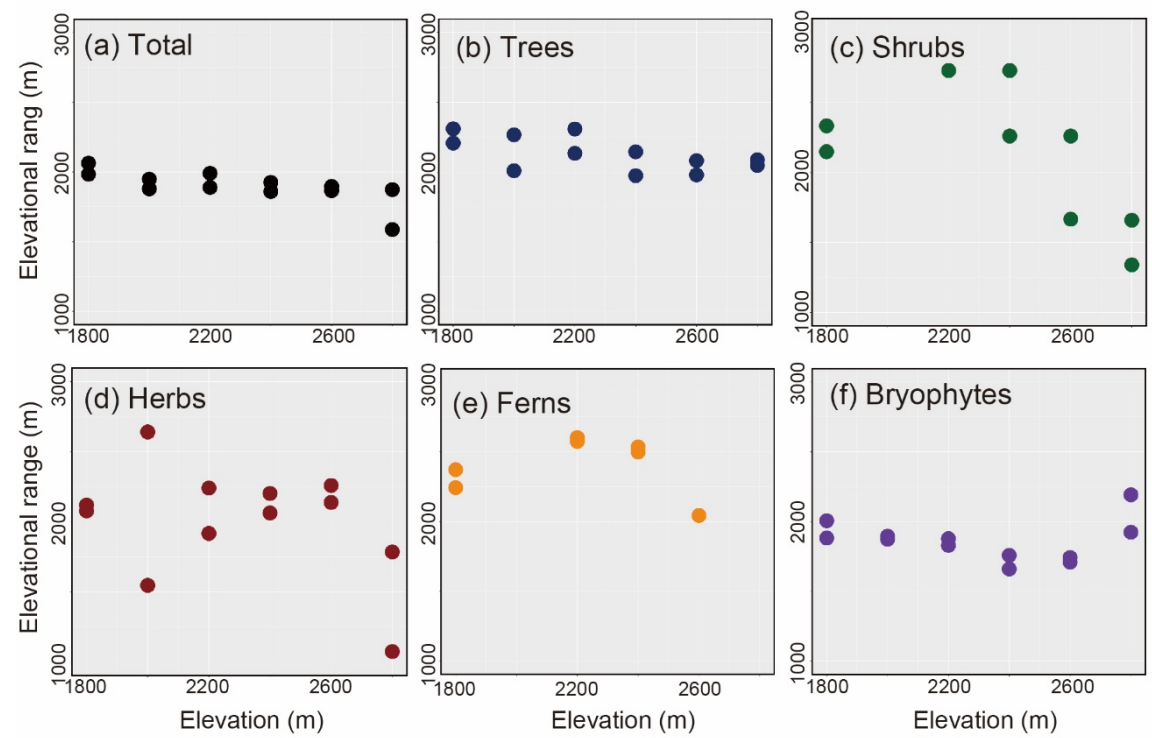

Figure 4

Figure 4.

\section{Data availability statement}

The datasets used in this study are available in the Supporting information.

\section{References}

Akiyama, H. (1983). Bryophytes of Mt. Hakusan 1. Hepaticopsida \& Anthocerotopsida. Annual report of Hakusan Nature Conservation Center, 9 , 13-24.

Akiyama, H. (1984). Bryophytes of Mt. Hakusan 2. Bryopsida. Annual report of Hakusan Nature Conservation Center, 11, 25-46.

Bhattarai, K. R., \& Vetaas, O. R. (2003). Variation in plant species richness of different life forms along a subtropical elevation gradient in the Himalayas, east Nepal. Global Ecology and Biogeography, 12 (4), 327-340. https://doi.org/10.1046/j.1466-822X.2003.00044.x

Bhattarai, K. R., \& Vetaas, O. R. (2006). Can Rapoport's rule explain tree species richness along the Himalayan elevation gradient, Nepal?Diversity and Distributions, 12 (4), 373-378. https://doi.org/10.1111/j.1366-9516.2006.00244.x

Biodiversity centre of Japan (2018). National vegetation survey database. Retrieved from http://gis.biodic.go.jp/webgis/files/veg_survey_db.zip

Bruun, H. H., Moen, J., Virtanen, R., Grytnes, J. A., Oksanen, L., \& Angerbjörn, A. (2006). Effects of altitude and topography on species richness of vascular plants, bryophytes and lichens in alpine communities. Journal of Vegetation Science, 17 (1), 37-46. https://doi.org/10.1111/j.1654-1103.2006.tb02421.x

Colwell, R. K. (2006). RangeModel A Monte Carlo simulation tool for assessing geometric constraints on species richness. Version 5. Retrieved from http://viceroy.eeb.uconn.edu/rangemodel.

Colwell, R. K., \& Hurtt, G. C. (1994). Nonbiological gradients in species richness and a spurious Rapoport effect. The American Naturalist, 144 (4), 570-595. 
Colwell, R. K., \& Lees, D. C. (2000). The mid-domain effect: geometric constraints on the geography of species richness. Trends in Ecology \& Evolution, 15 (2), 70-76. https://doi.org/10.1016/S0169-5347(99)01767-X

Colwell, R. K., Rahbek, C., \& Gotelli, Nicholas J. (2004). The mid-domain effect and species richness patterns: what have we learned so far? The American Naturalist, 163 (3), E1-E23. https://doi.org/10.1086/382056

Culmsee, H., \& Leuschner, C. (2013). Consistent patterns of elevational change in tree taxonomic and phylogenetic diversity across Malesian mountain forests. Journal of Biogeography, 40 (10), 1997-2010. https://doi.org/10.1111/jbi.12138

Duckworth, J. C., Kent, M., \& Ramsay, P. M. (2000). Plant functional types: an alternative to taxonomic plant community description in biogeography? Progress in Physical Geography, 24, 515-542. https://doi.org/10.1177/030913330002400403

Dullinger, S., Gattringer, A., Thuiller, W., Moser, D., Zimmermann, N. E., Guisan, A., . . . Hulber, K. (2012). Extinction debt of high-mountain plants under twenty-first-century climate change.Nature Climate Change, 2 , 619. https://doi.org/10.1038/nclimate1514

Engler, R., Randin, C. F., Thuiller, W., Dullinger, S., Zimmermann, N. E., AraUJo, M. B., . . . Guisan, A. (2011). 21st century climate change threatens mountain flora unequally across Europe. Global Change Biology, 17 (7), 2330-2341. https://doi.org/10.1111/j.1365-2486.2010.02393.x

Grau, O., Grytnes, J. A., \& Birks, H. (2007). A comparison of altitudinal species richness patterns of bryophytes with other plant groups in Nepal, Central Himalaya. Journal of Biogeography, 34 (11), 19071915. https://doi.org/10.1111/j.1365-2699.2007.01745.x

Grytnes, J. A. (2003). Species-richness patterns of vascular plants along seven altitudinal transects in Norway. Ecography, 26 (3), 291-300. https://doi.org/10.1034/j.1600-0587.2003.03358.x

Grytnes, J. A., Heegaard, E., \& Ihlen, P. G. (2006). Species richness of vascular plants, bryophytes, and lichens along an altitudinal gradient in western Norway. Acta Oecologica, 29 (3), 241-246. https://doi.org/10.1016/j.actao.2005.10.007

Grytnes, J. A., Heegaard, E., \& Romdal, T. S. (2008). Can the mass effect explain the midaltitudinal peak in vascular plant species richness? Basic and Applied Ecology, 9 (4), 373-382. https://doi.org/10.1016/j.baae.2007.05.001

Hardy, J. P., Groffman, P. M., Fitzhugh, R. D., Henry, K. S., Welman, A. T., Demers, J. D., . . . Nolan, S. (2001). Snow depth manipulation and its influence on soil frost and water dynamics in a northern hardwood forest. Biogeochemistry, 56 (2), 151-174. https://doi.org/10.1023/a:1013036803050

Hattori, S. (1958). The hepaticae of Ontake Mountain, middle Japan. Journal of Hattori Botanical Laboratory, $20,33-53$.

Inoue, H. (1981). Hepaticae of Mt. Fuji, central Japan. Memoirs of the National Science Museum, 14 , $59-74$.

Jan, H., \& Wolf, D. (1993). Diversity patterns and biomass of epiphytic bryophytes and lichens along an altitudinal gradient in the Northern Andes. Annals of the Missouri Botanical Garden , 80 (4), 928-960. https://doi:10.2307/2399938

Japan Meteorological Agency. (2018). Past meteorological data (Nobeyama). Retrieved from http://www.data.jma.go.jp/obd/stats/etrn/view/nml_amd_ym.php?prec_no=48\&block_no $=0415 \&$ year $=\&$ month $=\&$ day $=\&$ view $=$

Jiang, Z., Ma, K., Liu, H., \& Tang, Z. (2018). A trait-based approach reveals the importance of biotic filter for elevational herb richness pattern. Journal of Biogeography, 45 (10), 2288-2298. https://doi.org/10.1111/jbi.13398 
Jung, S. H., Lim, C. H., Kim, A. R., Woo, D. M., Kwon, H. J., Cho, Y. C., \& Lee, C. S. (2017). Edge effects confirmed at the clear-cut area of Korean red pine forest in Uljin, eastern Korea. Journal of Ecology and Environment, 41 (1), 36. https://doi.org/10.1186/s41610-017-0051-2

Kodama, T. (1971). Liverworts of Kinki District, central Japan, preserved in the Osaka Museum of Natural History. Part 1 . Osaka, Japan: Osaka Museum of Natural History (in Japanese).

Kodama, T. (1972). Liverworts of Kinki District, central Japan, preserved in the Osaka Museum of Natural History. Part 2 . Osaka, Japan: Osaka Museum of Natural History (in Japanese).

Koleff, P., Gaston, K. J., \& Lennon, J. J. (2003). Measuring beta diversity for presence-absence data. Journal of Animal Ecology, 72 (3), 367-382. https://doi.org/10.1046/j.1365-2656.2003.00710.x

Korner, C. (2003). Carbon limitation in trees. Journal of Ecology, 91 (1), 4-17. https://doi.org/10.1046/j.1365-2745.2003.00742.x

Korner, C. (2007). The use of 'altitude' in ecological research.Trends in Ecology 86 Evolution, 22 (11), 569-574. https://doi.org/10.1016/j.tree.2007.09.006

Lee, C.-B., Chun, J.-H., Song, H.-K., \& Cho, H.-J. (2013). Altitudinal patterns of plant species richness on the Baekdudaegan Mountains, South Korea: mid-domain effect, area, climate, and Rapoport's rule.Ecological Research, 28 (1), 67-79. https://doi.org/10.1007/s11284-012-1001-1

Lee, T. D., \& La Roi, G. H. (1979). Bryophyte and understory vascular plant beta diversity in relation to moisture and elevation gradients. Vegetation, 40 (1), 29-38.

Litaor, M. I., Williams, M., \& Seastedt, T. R. (2008). Topographic controls on snow distribution, soil moisture, and species diversity of herbaceous alpine vegetation, Niwot Ridge, Colorado. Journal of Geophysical Research: Biogeosciences, 113, G02008. https://doi.org/10.1029/2007JG000419

Lomolino, M. V. (2001). Elevation gradients of species-density: historical and prospective views. Global Ecology and Biogeography, 10 (1), 3-13. https://doi.org/10.1046/j.1466-822x.2001.00229.x

Manabe, S. (1957). On the modification of air-mass over the Japan Sea when the outburst of cold air predominates. Journal of the Meteorological Society of Japan. Ser. II, 35 (6), 311-326. https://doi.org/10.2151/jmsj1923.35.6_311

Marschall, M., \& Proctor, M. C. F. (2004). Are bryophytes shade plants? Photosynthetic light responses and proportions of chlorophyll a, chlorophyll b and total carotenoids. Annals of Botany ,94 (4), 593-603. https://doi:10.1093/aob/mch178

Masuzaki, H., \& Katagiri, T. (2010). Liverworts on Mt. Kitadake \& Mt. Ainodake. In T. Masuzawa (Ed.), Minami alps: geography and biota(pp. 257-276). Shizuoka, Japan: Shizuoka Prefecture (in Japanese).

Miyajima, Y., Sato, T., \& Takahashi, K. (2007). Altitudinal changes in vegetation of tree, herb and fern species on Mount Norikura, central Japan. Vegetation Science, 24 (1), 29-40. https://doi.org/10.15031/vegsci.24.29

Nabe-Nielsen, J., Normand, S., Hui, F. K., Stewart, L., Bay, C., Nabe-Nielsen, L. I., \& Schmidt, N. M. (2017). Plant community composition and species richness in the High Arctic tundra: From the present to the future. Ecology and Evolution, 7 (23), 10233-10242. https://doi.org/10.1002/ece3.3496

Nogues-Bravo, D., Araujo, M. B., Errea, M. P., \& Martinez-Rica, J. P. (2007). Exposure of global mountain systems to climate warming during the 21st Century. Global Environmental Change, 17 (3), 420-428. https://doi.org/10.1016/j.gloenvcha.2006.11.007

Okitsu, S. (1984). Comparative studies on the Japanese alpine zone with special reference to the ecology of Pinus pumila thickets.Geographical Review of Japan Ser. A, 57 (11), 791-802. https://doi.org/10.4157/grj1984a.57.11_791 (in Japanese) 
Riehl, H. (1962). Jet streams of the atmosphere. Fort Collins, Colorado: Colorado State University.

Roberts, M. R., \& Zhu, L. (2002). Early response of the herbaceous layer to harvesting in a mixed coniferous-deciduous forest in New Brunswick, Canada. Forest Ecology and Management , 155 (1), 1731. https://doi.org/10.1016/S0378-1127(01)00544-8

Rosbakh, S., Leingartner, A., Hoiss, B., Krauss, J., Steffan-Dewenter, I., \& Poschlod, P. (2017). Contrasting effects of extreme drought and snowmelt patterns on mountain plants along an elevation gradient.Frontiers in plant science , 8 , 1478-1478. https://doi:10.3389/fpls.2017.01478

Roux, P. C., Aalto, J., \& Luoto, M. (2013). Soil moisture's underestimated role in climate change impact modelling in low-energy systems. Global Change Biology, 19 (10), 2965-2975. https://doi.org/10.1111/gcb.12286

Sanchez-Gonzalez, A., \& Lopez-Mata, L. (2005). Plant species richness and diversity along an altitudinal gradient in the Sierra Nevada, Mexico. Diversity and Distributions, 11 (6), 567-575. https://doi.org/10.1111/j.1366-9516.2005.00186.x

Shmida, A., \& Wilson, M. V. (1985). Biological determinants of species diversity. Journal of Biogeography , 1-20. https://doi.org/10.2307/2845026

Song, B., Sun, L., Lev-Yadun, S., Moles, A. T., Zhang, S., Jiang, X., . . . Sun, H. (2020). Plants are more likely to be spiny at mid-elevations in the Qinghai-Tibetan Plateau, south-western China. Journal of Biogeography, 47 (1), 250-260. https://doi.org/10.1111/jbi.13724

Song, X., Hogan, J. A., Brown, C., Cao, M., \& Yang, J. (2017). Snow damage to the canopy facilitates alien weed invasion in a subtropical montane primary forest in southwestern China. Forest Ecology and Management, 391, 275-281. https://doi.org/10.1016/j.foreco.2017.02.031

Speziale, K. L., Ruggiero, A., \& Ezcurra, C. (2010). Plant species richness-environment relationships across the Subantarctic-Patagonian transition zone. Journal of Biogeography, 37 (3), 449-464. https://doi.org/10.1111/j.1365-2699.2009.02213.x

Stehn, S. E., Webster, C. R., Glime, J. M., \& Jenkins, M. A. (2010). Elevational gradients of bryophyte diversity, life forms, and community assemblage in the southern Appalachian Mountains. Canadian Journal of Forest Research , 40(11) , 2164-2174. https://doi:10.1139/X10-156

Stevens, G. C. (1992). The elevational gradient in altitudinal range: an extension of Rapoport's latitudinal rule to altitude. The American Naturalist, 140 (6), 893-911. https://doi.org/10.1139/X10-156

Sun, S.-Q., Wu, Y.-H., Wang, G.-X., Zhou, J., Yu, D., Bing, H.-J., \& Luo, J. (2013). Bryophyte species richness and composition along an altitudinal gradient in Gongga Mountain, China. PLoS ONE, 8 (3), e58131. https://doi.org/10.1371/journal.pone.0058131

Takaki, N., Amakawa, T., Osada, T., \& Sakuma, E. (1970). bryophytes flora of Mt. kaikoma, Mt. Senjo and Mt. Kitadake (Southern Japan Alps). Journal of Hattori Botanical Laboratory, 33 , 171-202.

Tanaka, T., \& Sato, T. (2013). Elevational patterns of fern species assemblages and richness in central Japan. Plant Ecology, 214 (9), 1189-1197. https://doi.org/10.1007/s11258-013-0243-5

Tanaka, T., \& Sato, T. (2014). Species richness of seed plants and ferns along a temperate elevational gradient in central Japan.Plant Ecology, 215 (11), 1299-1311. https://doi.org/10.1007/s11258-014-0388-x

Thomas, S. C., Halpern, C. B., Falk, D. A., Liguori, D. A., \& Austin, K. A. (1999). Plant diversity in managed forests: understory responses to thinning and fertilization. Ecological Applications ,9 (3), 864-879. https://doi:10.1890/1051-0761(1999)009[0864:Pdimfu]2.0.Co;2

Trigas, P., Panitsa, M., \& Tsiftsis, S. (2013). Elevational gradient of vascular plant species richness and endemism in Crete-the effect of post-isolation mountain uplift on a continental island system.PLoS One, 8 
(3), e59425. https://doi.org/10.1371/journal.pone.0059425

Ueda, H., Kibe, A., Saitoh, M., \& Inoue, T. (2015). Snowfall variations in Japan and its linkage with tropical forcing. International Journal of Climatology, 35 (6), 991-998. https://doi.org/10.1002/joc.4032

Zhou, Y., Ochola, A. C., Njogu, A. W., Boru, B. H., Mwachala, G., Hu, G., . . . Wang, Q. (2019). The species richness pattern of vascular plants along a tropical elevational gradient and the test of elevational Rapoport's rule depend on different life-forms and phytogeographic affinities. Ecology and Evolution, 9 (8), 4495-4503. https://doi.org/10.1002/ece3.5027

\section{Biosketch}

Yoshitaka Oishi is an associate professor at the Fukui Prefectural University, Japan. His research interests are bryophyte diversity and its response to environmental changes. The importance of moss in the culture of Japan is also a topic of interest to him.
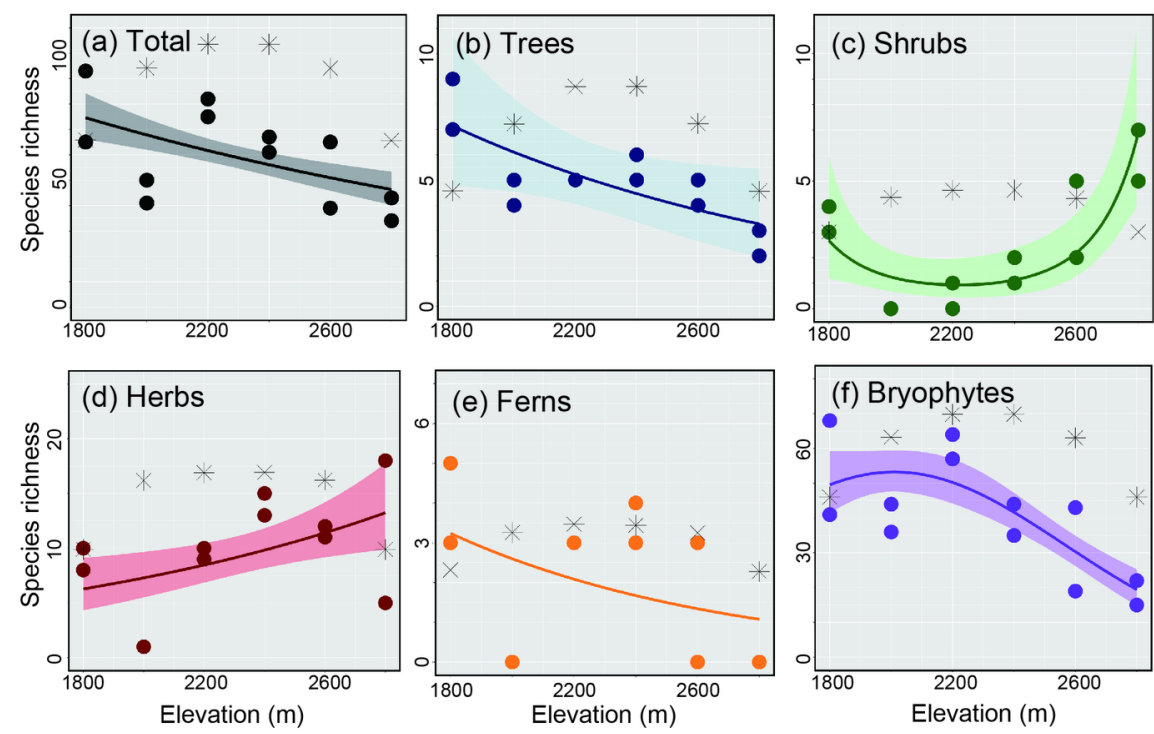

Figure 1 

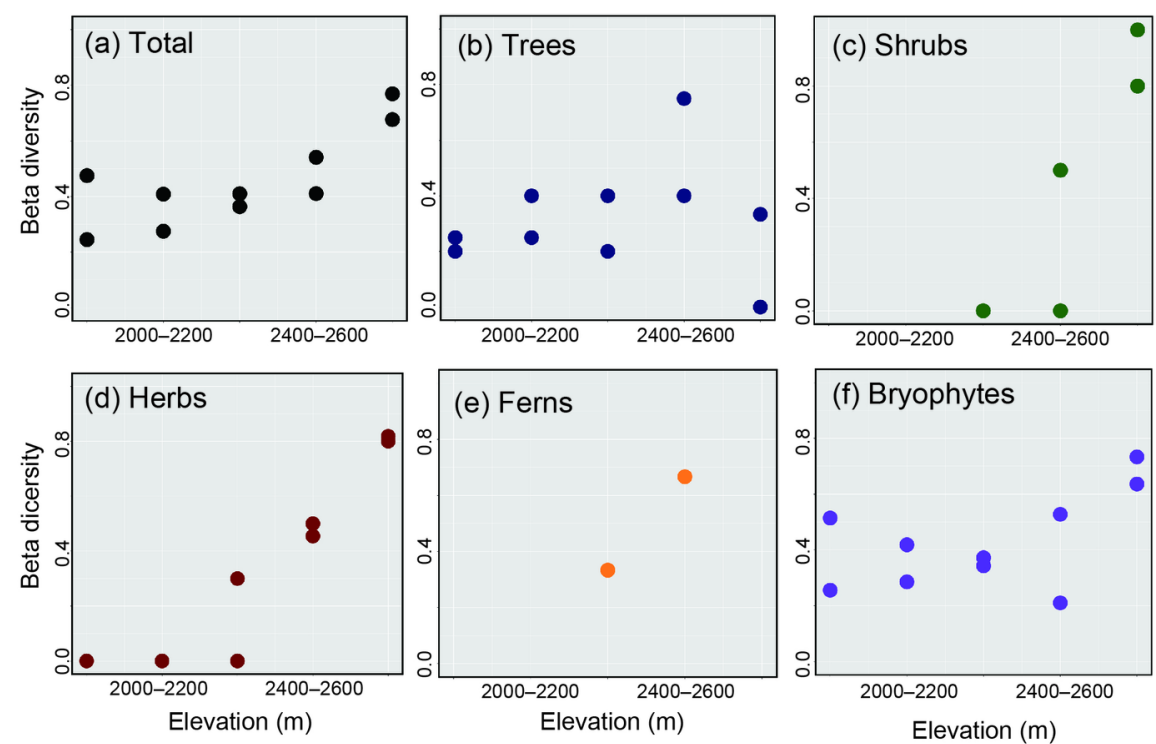

Figure 2
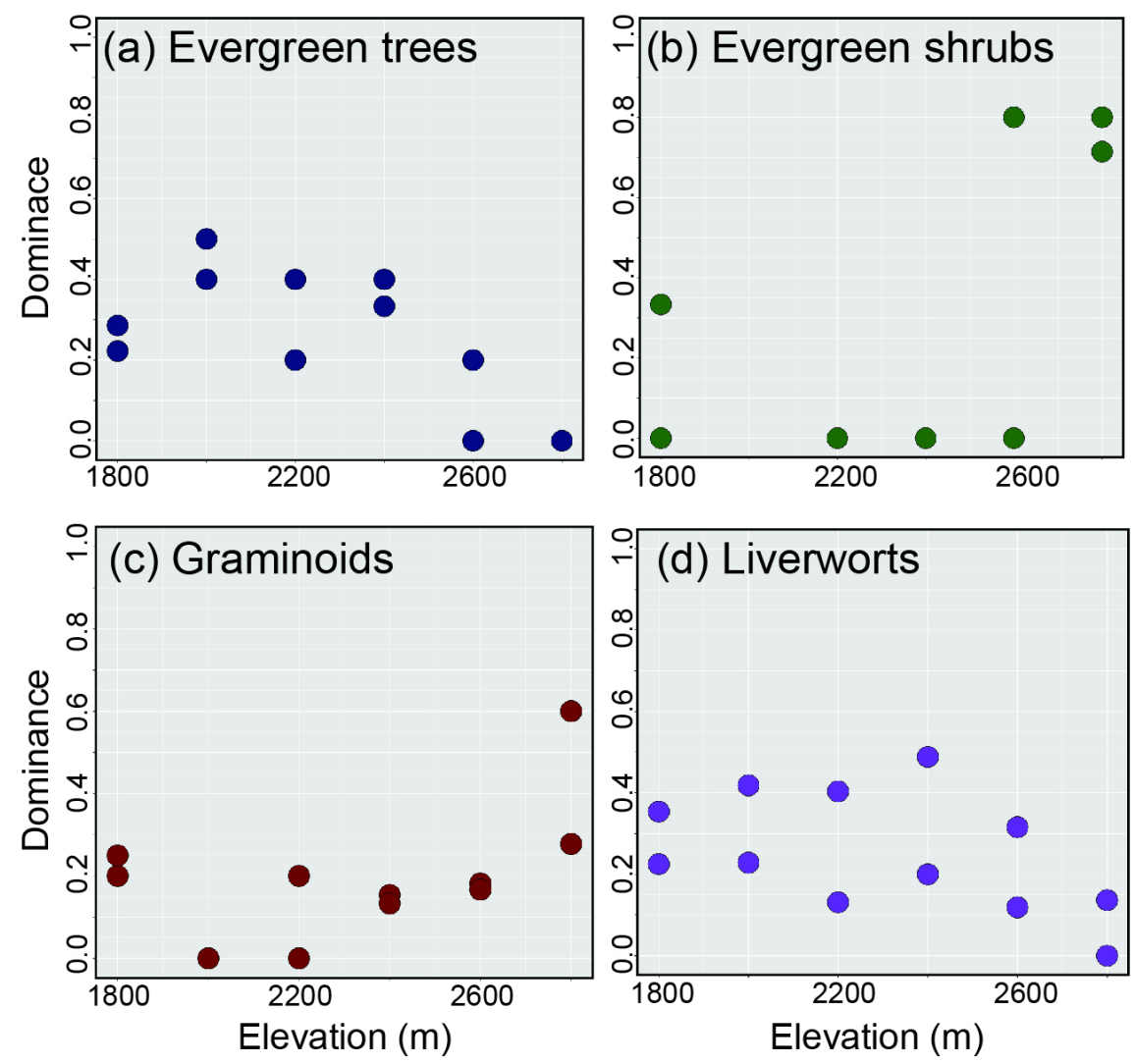

Figure 3 

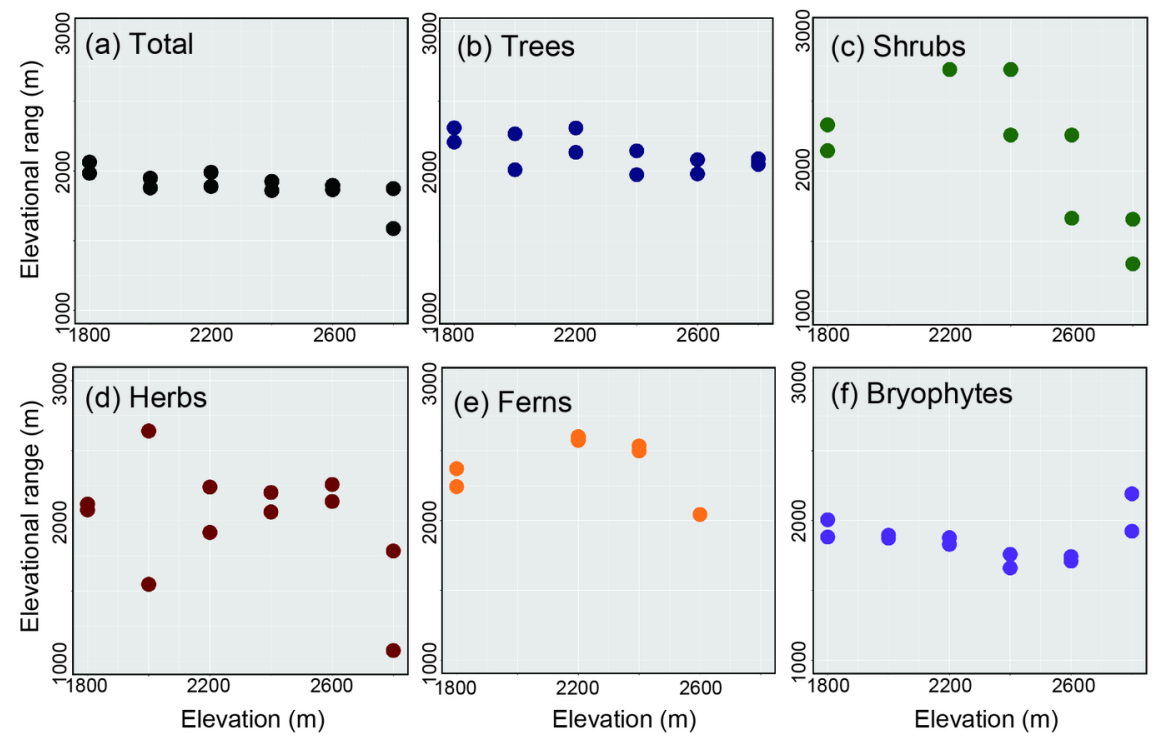

Figure 4 